\title{
Master narratives and narratives as told by people with mental health and drug problems
}

Hanne Thommesen, Associate professor, Bodø University College, Norway.

E-mail: Hanne.Thommesen@hibo.no 


\begin{abstract}
This article examines the role of master narratives in self-narratives told by people with both mental health and drug problems. It is based on stories told by people who have both mental health and drug problems. However, their substance abuse has become their most dominant characteristic in their lives. The storytellers or the interviewees attempt to describe their background, their experience and what they call churning thoughts, while their stories are also infiltrated and dominated by master narratives about the drug abuser.
\end{abstract}

\title{
Keywords:
}

Master narratives, self-narratives, counter narratives, drug abuse, dual diagnosis, churning thoughts, mental health problem, street capital, bodily dispositions and unusual experience. Introduction

The aim of the article is to show that the interviewees' self-narratives are influenced by what they explain to be the culture's master narratives about drug abusers. These narratives, my interviewees tell me, make it difficult for them to focus on other aspects of themselves than their drug abuser-status. Master narratives are basic narratives which indicate relatively fixed common perceptions in a culture. The narratives are to be found on an unreflected upon and can therefore direct our understanding of situations, actions and people without us being aware of this (Frønes 2001). Thorne and McLean (2003) describe the narratives as culturally value-laden positions produced by social authorities to determine what is significant. The function of the narratives is to maintain social order by being cultural standards to which members of society feel obliged to adhere. The narratives can also be used to create distance from people, actions and situations which may threaten social order.

The article deals with how the interviewees' self-narratives are linked to their experiences and activities, to other people's perspectives and to master narratives about people with drug abuserstatus. The format for this text is as follows; the first section will describe the study that gathers data to this article, and the interviewees. The second section will seek to explore different master narratives linked to drug abusers. The third and sixth section will explore and describe selfnarrative in contrast and connection to the interviewees' view of others in the community, in the third section towards the majority and in the sixth section to narratives about other drug abusers. The fourth section will focus on the interviewee's street capital and their bodily dispositions, and the seventh section will explore the role of other people's perspectives in the interviewees' selfnarrative. The fifth section will offer an explanation of what "churning thoughts" are, and what the interviewees said are their main problems. The final section will offer a conclusion or more precisely a reason raison d'être for this article.

\section{About the study and the interviewees}

This article is based on a qualitatively oriented investigation. In the study I was interested in the storytellers' point of view, and I therefore chose to conduct open interviews. This implies, that interviews are unavoidably active meaning-making ventures (Holstein and Gubrium 2004); but in this study I wanted to try to listen carefully to the particular theme the interviewees want to talk about. I therefore had only prepared one question for the interview situation. This question was: Why did you show up for interview? Most of the respondents said that they came because they wanted to contribute towards changing the welfare state and the service system for children and youth. Some of them had other reasons such as Mads, who told of:

"I think it is very good to be able to tell somebody about this, because I have a feeling - it is difficult to explain it - of morality inside. It says that there is something wrong, at least in terms of what I have learnt. I want to tell my story because this is a situation that anybody 
could end up in, independent of one's own free will".

Mads indicates that all of us could end up as drug abusers. However, as we shall see, we have a tendency to create narratives to tell that that are not true. On the basis of the interviewees' reason for participation in the study we - the interviewees and I - start to talk about the interviewees' experience, skills and knowledge. Of course I ask more questions and the respondents give me more answers, but in respect of the young people I only ask questions about the topic already introduced.

The aim of the study was to describe, explore and understand the circumstances of life and the point of view of young people with both mental health and drug problems - so-called dual diagnosis (Thommesen 2008). In this article the aim is purely to look at and explore how master narratives influence personal narratives. When I analyze the data from the study, it becomes clear to me that, within the interviewees' stories, there was and underlying story, a story about an abuser-figure they compare themselves with. This fictional figure was created true to one or several master narratives relating to people who use narcotic substances.

In the study I interview seventeen young people; ten men and seven women. They were born between 1974 and 1984 with an average age at the first interview of 26. They came from all over Norway. At the time the study took place, they moved around from place to place, from north to south and from east to west in the country. They also moved around from institution to institution, from homes to the street, from prison to shelters. All of them had both mental health and drug problems. They had all been given several and severe mental diagnoses - such as schizophrenia, antisocial personality disorder, bipolar disorder, manic depressive psychosis and so on -, from the health care system, and they had lived in close encounters with the social and mental health system nearly all their lives.

I recruited the seventeen people with mental health and drug problems through door openers from the service system or from drug abuser organisations. These door openers gave their clients or co-members, which fitted my target group, an information script about the study and my phone number. The respondents then called me or they ask a service provider to call me in order for them to give me their phone number. All seventeen were unknown to me previously before I met them for the first interview, but now I have sporadic contact with them all, or more precisely with sixteen of them. Dagfinn is unfortunately dead. The interviews took place at places chosen by the respondents: cafés, mental health institutions, private homes, offices in the social system, schools, working places and my office as well.

All seventeen were interviewed several times - between two and five times. My intention was to do two interviews with each one of them with one year between the interviews. But I learned that young people with drug and mental health problems had a lot they wanted to talk about. After just one interview with one respondent it was obvious to me that some stories are difficult to tell about for the interviewees and some are difficult to listen to for me, this forcing us to meet several times each year. All the interviews were conducted by me, using a tape recorder. The data material consisted of 47 research interviews, and the transcription consisted of more than 1000 pages of text.

The study has been reported to Norwegian Social Science Data Services (NSD), and the interviewees have been given fictional alphabetical names in the order I interviewed them, from August to Rita. Through the interviews I have gained access to their personal stories. I use quotes from some of the stories in the article, but the conclusions drawn have been reached on the basis of the data material as a whole.

\section{Master narratives about the drug abuser}

The stories that people tell about themselves reflect peoples' experience, as they see it and 
as they wish to have others see it (G. Becker 1999). Our personal narratives are important to us because they relate about our past, but also because they make sense of the present. Though telling stories we organize, display and work through our experiences. We attempt to create coherence and give meaning to our lives by learning to read time backwards (ibid 1999). But people not only tell stories about their life to create life stories and personal identities, they also use storytelling to shape and form the culture.

Master narratives are hallmarks that act to universalize and cast dialogues in binary, contrasting categories that support the maintenance of dominant groups. The master narrative operates as a script that specifies and controls how social processes and living are carried out (Stanley 2009). We can say that members in marginalized groups, such as people with dual diagnosis, have had little input in the shaping of these narratives. Their input is just used to evolve and maintain the narratives, not too create new ones. These master narratives, so to speak, create and reinforce power structures in society. They also ignore the heterogeneity or variety of human existence (Frønes 2001). That is to say, on the one hand, master narratives are created and sustained by every one of us in the ongoing flow of narrative, but on the other hand, the master narratives have the power to influence and create opportunities and restrictions for our life and our personal narratives.

There are a number of narratives about people with mental health and drug problems. Some are linked to the fact that the person has drug abuse problems and some are linked to the fact that they suffer from both mental health and abuse problems. In the first case there are master narratives about drug abusers. These narratives describe people who do not have control over their substance abuse. Their abuse is described as being the organised principle in their everyday lives. The narratives also communicate that the drug abuser has often had difficulties at school, that they come from families with few resources, that they are poorly educated, that they commit crimes, have a poor work ethic, a poor diet, few pastimes and that they blame society and the social services for their substance abuse.

In the second case very unattractive master narratives are told about people with mental health and abuse problems. When the media and research focus on adults with mental health and drug abuse-related problems they tell of poor living conditions, people short of resources who cannot take care of themselves, crime and diminished responsibility at the time of committing the act (Rosenthal 2003, Evens and Sullivan 2001). The media, research and public enquiries also produce stories about a lack of treatment places and about people who fall between various treatment regimes - addiction services and psychiatry services (Bucciarelli 2005, NOU 2003:4). Strand claims that the media image is influenced by a "basic distance and contrast between the abuser and the "normal person'" (Strand 2005:74). In my view the distance between the drug abuser and the rest of us is not only found in the news image, but also in master narratives about drug abusers. The essence of the narratives is that those who develop a dependency on narcotic substances are not like us - the majority - who have an acceptable (or hidden) relationship with narcotic substances.

We can say that these two forms of master narratives about the drug abuser and people with dual diagnosis are in one sense of a masculine nature. When I tried to recruit respondents for my study, I heard another narrative. This narrative differentiates between two kinds of drug abusers: on the one hand male abusers and on the other hand female abusers. The male abusers correspond with the abuser mentioned in the master narratives above. The narrative about the female abusers differs somewhat. The service providers who I contacted to recruit respondents to the study told me that there were few women with dual diagnosis, and that women do not need so much service as men, or that they have children and therefore avoid the service system. This narrative gives the impression that abuse is experienced as more stigmatic for female abusers than for male abusers, that young woman preferably use tablets and not so often heroin, and that women are not such a provocative 
problem for their surroundings. Consequently this narrative tells that drug abuse amongst women means less trouble for relatives and society, and is therefore less visible than men's abuse.

Master narratives about school pupils drawn to drug milieus often give the impression that these are boys and girls wishing to live their lives opportunistically, outside the norms of society or in opposition to the guidelines defined as culturally desirable. These children are said to have a negative attitude to social obligations and personal self-denial and they are perceived as prioritising narcotic substances over and above school or work (Fekjær 2004). Bendik was almost 17 when he began using narcotic substances. He said he had a late debut:

"It was first when I started at upper secondary school that all things started slide. I hadn't smoked cigarettes once before then. Those who started dropping out by smoking cigarettes and hashish did it in junior secondary - between the seventh, eighth and ninth grades. I wasn't part of that gang. I did my own thing. I was hard working and did what I should. But something or other happened when I started upper secondary school. Without me knowing entirely what happened. There must have been something lying latent. It was almost like flicking a switch. From doing everything I should to beginning to play truant and smoking cigarettes and hashish."

The quote forms a small part of Bendik's narrative about his relationship to narcotic substances. In his environment there were clear perceptions about who "drops out" of school and when this happens. According to Bendik, those who drop out of junior secondary school are those who start using beer, tobacco and hashish. These children break conventions and Bendik did not consider himself to be one of them. He used words such as responsibility, hardworking and obedience to describe himself. Such character traits are incompatible with his perception of who drops out of school and who gradually develops a dependency on narcotic substances.

As Bendik indicates, the master narratives communicate that those who start early on alcohol and tobacco develop substance dependency as adults. This narrative is founded on society's collective experience. This experience is confirmed, reinforced and related by research which tends to be quantitative research about drug abuse. Researchers find a significant connection between starting early and developing substance dependency (Kandel 2002). In a Norwegian study about teenagers' substance use, the researchers were interested in the time of the debut of alcohol consumption and the connection between the time of the debut and alcohol consumption later in life (Pedersen 1998). The study paints a pattern showing that the time of the debut for trying alcohol varies from person to person. The great majority begin drinking alcohol when they are between 10 and 20 years old. At the age of 15 around half of teenagers have had their debut with alcohol. The findings of the above study also show that the earlier a person starts using alcohol the greater the consumption of alcohol by the person concerned becomes through the teenage years. It also indicates that there may be a certain connection between the time of the debut and the development of other drug abuse problems at the end of the teenage years (Pedersen 1998). In my view one of the most interesting things about the results of the study is that at least half of Norwegian youths make their debut using narcotic substances before these are legal for them. This implies that the drug abuser and we others are not that different in terms of our debut. Most of us start on alcohol before it is legal for us. The drug abusers are perhaps more like us than we would like to admit. This relationship is masked by the master narratives and the narratives can therefore continue to create order and put distance between them and us.

\section{Outsiders and Second-rate}

When speaking about their childhood, the interviewees described themselves in contrast to other children among their siblings, in the neighbourhood or at school. "I have been different since I 
was little." The words are Nina's, but the vast majority of respondents in the study could have used the same words. For the interviewees the way towards to substance abuse has moved via an increasing awareness of themselves being different to others (as an outsider). Howard Becker uses the term "outsiders" to refer to individuals or groups whom other people define as deviants and who therefore remain outside the circle of "normal" members of society (Becker 1991). He stresses that labelling someone a deviant - outsider - may contribute to pushing the person further out towards the margins of society than the person might otherwise have gone. A vital point here is that the deviation is not a characteristic present in the actions of one person. The deviation should instead be seen as a result of a process involving other people's reactions to the person's actions. The deviation lies in the interaction between the person performing the action and those reacting to the action (Becker 1991). Becker's (and my) theoretical project does not involve explaining the essence of deviation. The ambition of this research is to describe how social categorisation has an effect on the lives of those who are categorised as deviant.

While the interviewees described themselves as being different to other children when they were growing up they also described how they perceived that being too different was not accepted. Their value as people was reduced by them becoming second-rate. Many of the interviewees for instance perceived themselves as being hard working at school; which is basically a positive quality. Nina told how she started school a year before the other children in the neighbourhood. After the first year of school the family moved and she started at a new school. At the new place she was moved down a year. The adults also decided that she should go to a speech therapist to change her dialect. "Just think that they wanted to get rid of my dialect," said Nina. She pointed out that she regards the forced change of dialect and moving down a year as criticism of her as a person. As she sees it the adults continued downgrading her during the period she was growing up. She was seen, but at the same time she was systematically overlooked or misinterpreted. In this way Nina developed problems with her self-esteem.

The dualism we and the others differentiate between two groups: (1) us and (2) the others. Who we are and who the others are is constructed by the situation in the social space. We and the others are based on a ranking in which some people are ranked above others (Søndergaard 2002). We in Group One (often the majority) are ranked above them in Group Two (often the minority). Group Two consists of those who are second-rate and who do not fit into the norms set by Group One. They are made outsiders. This is therefore about power structures. Those who are higher ranking have the power to define what is acceptable behaviour, clothes or skills, and what is not. Individuals are positioned; inside or outside, as master or servant (ibid 2002). Those who are different from the norm (or the people defined as normal) are not considered equal. They are not respected for their individuality. They are seen, but overlooked, and they are not considered whole people (Sennet 2003). Sennet points out that this creates people who do not resemble each other rarely experiencing or managing to give mutual respect to one another before seeing the resemblance between themselves and the other person. The interviewees describe a lack of recognition for their distinctive characteristics and subsequent attempts at medical or social correction as the original cause of them considering themselves downgraded as persons and the system maintaining this.

At the same time, neither Nina nor Bendik confirm the master narrative that children who are drawn towards narcotic substances do not perform well at school and have an early debut using narcotic substances. Both initially did well at school and made a late debut using narcotic substances. However, neither of them now has any education beyond upper secondary school, and they therefore confirm the master narrative that drug abusers are poorly educated.

\section{Street capital and bodily dispositions}

Every single one of us is formed by the life we have lived. What we do and our relationships 
contribute to providing us with experience and skills. The interviewees' narratives contain countless descriptions of their somewhat unusual experience. This means experiences which are different to the experiences of the majority of the population. The interviewees have experience of bullying, illness, incest, rape and other violent episodes, diagnosis processes, lengthy stays in institutions, homelessness and unemployment. However, they have little experience of ordinary working life, despite the fact that they have all had income-earning activities. Some of these activities are regarded as criminal activity. For example, most of them have had various forms of cash-in-hand work. Many have sold and smuggled drugs and they have committed burglaries, stolen and acquired money in different ways. The interviewees also stressed that living in an institution, being in prison or on the street do not cost anything, and therefore do not require an income. The interviewees' familiarity with narcotic substances has also given them many similar but relatively unusual experiences. They all have experience of abusing narcotic substances, they have acquired knowledge of various medications and illegal narcotic substances and the various effects of these. They all also have extensive experience of negotiating social security benefits from the many different offices of the welfare state. All these experiences can contribute to making them equal, and to resembling the drug abuser in the master narrative in other people's eyes.

The interviewees' unusual experiences contribute to the fact that they can at times be categorised as prisoners, psychiatric patients, drug abusers and homeless. There are stigmatised attitudes in all these categories. This means that their experiences give them "stigmata" which have negative consequences for them in social contexts (Goffman 1990). For instance people with previous convictions have greater difficulty than others in accessing the labour and housing markets (Waterston 1993). They also have difficulties with their family. Dagfinn says this:

"I feel provoked that I am so worthless for my family that they even do not want to talk to me. This happens at for example weddings and family gatherings. I do not count for them, so they overlook me and do not speak to me".

Stigma is about being reduced as a person, because someone deviates from the norm as a person in one way or another - you are not regarded as culturally and morally acceptable individuals. If we divide the population in two, on the basis of experience of imprisonment a distance is created between those who have had, and those who have not had this experience. A fellowship is also created amongst those who have this type of experience. Such fellowship of experience as that amongst ex-prisoners (or drug abusers) is not a fellowship in which the members necessarily have the same interests or spend time together. The fellowship is a category fellowship. This means a fellowship which is not first and foremost about social relationships, but about having a certain type of experience, behaviour or similarity.

Even though category fellowships are not social fellowships, they nevertheless contribute to somebody's self-narrative and self-knowledge. Members of the category have accumulated a related habitus, a habitus which tells others and themselves that they are outsiders. Bourdieu developed the concept of habitus and he says that "Habitus is a socialized subjectivity" (Bourdieu and Wacquant 1992:126). This means that habitus is based on someone's previous experiences, converted into physically manifested dispositions. Unusual experiences produce unusual bodily dispositions. The interviewees' unusual experiences have entered their bodies and many of their current reactions are based on handling fear and surviving. Bourdieu's aim in developing the concept of habitus is to circumvent the distinction between structure and actor. He emphasises that an individual is marked by previous experiences and to a greater degree by experiences that are repeated. By being marked by their experiences, an individual is also marked by the economic, social and cultural conditions (and narratives) in which the person concerned lives. Habitus must not be perceived as determinant. It simply gives an individual dispositions and tendencies 
- seen in this way an individual may, if he or she wishes, act contrary to their bodily dispositions. Bourdieu's concept of habitus is closely linked to his concepts of capital and social fields. Rita told of:

"I sense that I have become a hard-bitten type, especially outwards. But it is like this: if there is some trouble, then the old me will come up again. Somehow the street girl breaks through. [...] I may be not having psychological side effect of my drug abuse, but anyway there is side effects".

According to Bourdieu, different groups in society have different amounts of financial and cultural capital. In his book Distinction (1984) Bourdieu positions occupational groups hierarchically in relation to one another in the social space on the basis of the occupational group's total capital. In his model/theory the social space is split into two main dimensions: financial capital and cultural capital. These two forms of capital form the basis for hierarchies and social differences (ibid 1984). The forms of capital are convertible. This means that, for example, financial capital can be converted into or compensate for lacking cultural capital. In the same way that Bourdieu splits the social space along a vertical axis (hierarchy), he also splits the social space along a horizontal axis, in distinct but overlapping social fields (Crossley 2001). According to Bourdieu a field can be understood as a space or a network with objective relations between various positions, where the positions are determined by virtue of their power or form of capital. A field is an arena in which conflicts are played out within the rules which contribute to constituting the field (Bourdieu and Wacquant 1992). On the basis of such an analytical approach most practising drug abusers would be positioned at the bottom of the social hierarchy (if we disregard the fact that "being a drug abuser" is not usually defined as an occupation). Rita says this:

"It is strange to come from a community where you are a master, and then come into society where you are nothing. Imagine a person who has earned 30000 Norwegian kroner a week, and then she must live for 3800 Norwegian kroner a month. She will also be looked at as a loser. Out there she is a person that is cool and pleasant - yes, they too exist. Out here she is criminal and a social dropout, and a person who has never done an honest piece of work in her life. Before she woke up every morning at five o'clock and took a train to the City to buy drugs. And she always came back to keep her appointments. In the other world is she not trustworthy. This is a cultural shock".

There do exist; however, hierarchies and conflicts amongst people who abuse drugs- Sandberg and Pedersen (2006) define the resources which decide whether an individual has success in a drug-milieu or on the street as street capital. They define the street as a field; although they acknowledge that in an orthodox interpretation of Bourdieu, the street does not have the characteristics a field usually has (Sandberg and Pedersen 2006:83). In their study of the activities of the lads who sell hashish along the Akerselva River in Oslo they demonstrate how these lads develop a bodily skill (habitus). One of Sandberg and Pedersen's points is that street capital is accumulated on the street and only earns respect there. When this skill becomes visible elsewhere (social field), it appears stigmatizing and excluding (Ibid 2006:82). The interviewees (theirs and mine) are skilled, but their skill cannot be converted, for example on the labor market. Dagfinn says: "I think I am a resourceful man, but this is all worthless if nobody else sees what I have to offer". Who is interested in burglary skills, smuggling skills or the skill of being remanded in custody?

\section{What's the main problem, churning thoughts or drug abuse?}

The personal narratives I have been told are overcrowded with suffering, illness, abuse, problems, discrimination and injustice. But what do they tell is their main problem? To explain this I have to start with the various drugs these young people I have interviewed had used or 
abused. (Unfortunately this is what they tell other people always do).

The interviewees prefer various substances, from alcohol and tablets to heroin. More than half of them - five men and four women - have experience of taking heroin with the help of syringes. Fillip has such experience. He tells how he suffers from churning thoughts, back pain, toothache and stomach problems. He uses narcotic substances to overcome these problems. He is not particular about what he uses, but his favourite is heroin. In addition to using heroin, he smokes hashish and tobacco and drinks alcohol. His life of drug abuse (and churning thoughts) has left its mark on his body. He has a stooping posture, is extremely thin, shuffles when he walks, struggles to get his body to function, and does not have many teeth in his mouth. In other wards his body reveals his drug abuse.

The treating authorities have, as I have told before, given the interviewees various different psychological and somatic diagnoses. Fillip says he has been diagnosed as having bipolar disorder, ADHD and hepatitis C. The most striking aspect of the interviewees' medical histories is that they have been given "more and more diagnoses on their record" throughout their lives. Nina told of how: "I was given my first diagnosis, clinical depression, when I was 13." And August told of how "First I was given the diagnosis histrionic personality disorder. But another psychiatrist said that I had paranoid psychosis". The interviewees are unsure whether their first diagnoses has been changed or whether both the old and new diagnoses are currently valid. From my perspective it looks as if the interviewees are burdened with many diagnoses and that they suffer from what they define as churning thoughts. Isak gave the following description of his churning thoughts:

"I get in a state that I think about lots of things at the same time. That means that I cannot manage to focus on one thing at a time. My thoughts just jump from one thing to another. You could say that if I try to dream myself to sleep and get these churning thoughts, then it works out badly. I cannot manage to stay focused on one thing at all. I cannot manage to stop the thought either".

Jenny said the following about her churning thoughts:

"There can be days when there are so many thoughts in my head and they are there at the same time. They are things that could have been done, should have been done; they may be things someone has said, something I saw on TV, something I have done, something I should have done differently. There are so many such thoughts at one time. It feels as if my head is a balloon which is being blown up. I end up just sitting apathetically and do not get anything done. I then have to try saying to myself that I should just take one thing at a time. The same applies to the activity in my body. Sometimes when it pumps itself up it feels like there is internal pressure pushing outwards; that's how it feels. It feels as if my body is going to explode."

When the interviewees describe their problems, they use words which have meaning for them; words which they themselves believe emphasise and communicate their challenges better than the psychiatrists' diagnoses. According to the interviewees many of their problems are linked to social "angst", physical tension and uninterrupted mental confusion. They consider these three expressions to be three different aspects of churning thoughts. Churning thoughts are described as a hotchpotch of thoughts and feelings which periodically occupy their bodies. The starting point, the content and extent of the churning thoughts, are described differently, but the result is identical. The churning thoughts make it difficult for them to keep up with what is happening around them and this therefore creates problems for their self-expression.

Churning thoughts can be perceived as a mental challenge, but, for the interviewees, churning thoughts are about their bodies and their experience to the same degree. Grethe describes how her thoughts and feelings have a physical character. She may experience them as a bad feeling and as voices within her body. In contrast, Dagfinn describes having feelings outside 
his body, not inside. The feelings make him depressed and he can experience the depressions as physical pain. The feelings he has outside his body actually create pain in his body. Erik describes thoughts which make him throw up, while Isak describes thoughts which make him walk and walk in a type of psychotic trance. Jenny tells how unrest in her body gives her churning thoughts, which in turn makes her aggressive. Aggression is one of the ways in which her churning thoughts are expressed; sleeping difficulties is another and drug abuse is a third. The other interviewees also describe churning thoughts being expressed as major mood swings, a strained relationship towards eating and a level of activity which bothers them. The latter may, on the one hand, involve an inability to act and, on the other, compulsive activity. Churning thoughts also often contribute to self-harm and, in extreme cases, attempted suicide.

All the interviewees specify that they have, or have had, both mental health and drug problems. They state that churning thoughts are their basic problem. They have had this problem for as long as they can remember. In the course of their lives they have collected many "unusual experiences" and these experiences intertwined with these churning thoughts. Today it is impossible for the interviewees to differentiate experience manifested physically from what they describe and name as churning thoughts, something which indirectly implies that their many unusual experiences escalate and define their churning thoughts. Even if churning thoughts are their basic problem, they point out that their consumption of narcotic substances has the greatest social consequences.

\section{Counter narratives - not like other drug abusers}

Perspective or narratives that run opposite or counter to the presumed order and system are called counter narratives. These narratives often arise out of individual or group experience that does not fit into the master narratives (Stanley 2009). Counter narratives act to deconstruct the master narratives, and offer alternatives to the dominant narratives of, for example, drug abusers. They provide multiple and individual stories about living as a person with drug problems or dual diagnosis.

It is the interviewees' relationship with first and foremost narcotic substances and the bodily peculiarities and experiences connected to drug abuse which is expressed in the social space. The individuals distinguish themselves from the majority and we pick them out in the townscape. They are visible as members of the group of drug abusers whereas they are invisible as individuals. The complexity of the individuality of each specific person is not present in social relations to strangers. For the interviewees the problem when they want to speak about their individuality is that most of them can be described in such a way that they confirm the master narratives about drug abusers, this also applies to the women in my study.

Grethe, for instance, has many similarities with the drug abusers in the master narratives. Her appearance, her marked body and her way of conducting herself in the world tell those around her that she abuses narcotic substances. Her existence revolves around narcotic substances, she commits crimes to finance her substance abuse, and she blames the support services and the school system for some of her problems. Nevertheless, Grethe is preoccupied with distancing herself from other drug abusers. The interviewees' self-narratives can be viewed as their efforts to portray and understand themselves as unique individuals. They are people, who abuse narcotic substances, but also people who have varying life stories and interests, people who suffer from churning thoughts, bad experiences and memories. The visibility which drug abuse causes makes other aspects of them invisible. They have acquired a "master status". Becker describes how individual negatively loaded categories about social deviation become master statuses overshadowing the persons' other statuses (Becker 1991). The category drug abuser is this type of category of deviation not only describing someone dependent on narcotic substances - it also describes something more. The interviewees tell of how they experience the meaning ascribed to the status as making them invisible. The status means that those around 
them make associations with the master narratives about drug abusers. This implies that there are expectations in the structure of society about how the role of drug abuser should be played. These expectations rob an individual abusing substance of an individual identity.

Grethe communicates that she has a cohabitant, a permanent residence and a dog. She is a rascal and she likes to play games. She likes to walk the dog, to read and to draw, but she works long hours to make money for narcotic substances and has little spare time for hobbies. She has been convicted, and she has served a sentence. This description of Grethe gives her individuality, but it also confirms the master narrative about the drug abuser. Her work to stand out with a unique identity does not differ from all other people's work on identity, but the task is more difficult because she no longer has the chance to start with a clean slate. Her drug abuse means that simple things are written into social norms and on her body, even before she speaks or acts. Other things cannot be communicated because of the marks drug abuse has left on her body and the preconception found in the structure of society. Grethe has an individuality which makes her different to, for example, August, who is also dependent on narcotic substances. Grethe is good with craftwork and drawing. She has good grades from primary and secondary school and she is in a long-term cohabitant relationship. August, on the other hand, is sporty and musical. $\mathrm{He}$ usually lives with his father and has never had a girlfriend. The problem for Grethe and August is that something about them and their lifestyle makes them equal anyway. Their status as drug abusers and the master narratives belonging to the status hide the individuality of each of them. When August speaks he is more explicit than Grethe in that he consistently talks about himself in contrast to other drug abusers. He says:

"I am a very unconventional drug abuser. All drug abusers would probably say that, but I am. For example, yesterday I ate a very great deal ... I go running in the mountains, I go fly fishing [...] or I box. I actually do a lot, so seen like that; I am really the wrong person to interview."

When August stresses what he likes he does it in contrast to the picture (or the narrative) he draws of a drug abuser. For him the typical drug abuser is someone who does not eat enough, enjoy the outdoors and is not active. This description does not fit him and he therefore reserves the right to be an "unconventional drug abuser". He wants to distance himself from others with abuse problems. However, it creates difficulties for him that those around him do not make the same distinction as he does. People close to him see him as a substance abuser, not as August. He continually attempted to appear as a unique person anyway (or because of this). Unlike Grethe, August neither has a cohabitant nor drawing skills, and he spends most of his time alone in his father's spare room. He has sought refuge with his father because he finds relationships difficult. If relationships become too close, he experiences this as the other people "breaking into his head". The municipality has made a local-authority flat available for him, but he rarely uses it. He does not feel safe there. The flats are poorly soundproofed and this means that, when August is in the flat, he finds that the sounds of the neighbours force their way into his churning thoughts. The municipal housing provision does not suit him. The provision does not take his mental health problems into account. When we categorise people by their similarities we make members of the same category more similar than they actually are. August is categorised as a drug abuser, but substance abusers are not completely identical. The offer of accommodation which suits one person abusing drugs does not suit someone else with similar problems. The drug abuse hinders the support services (and the rest of us) in seeing Augusts' mental health problems and taking them into account, despite his medical diagnoses. His substance abuse is made the overriding problem. He is a drug abuser, not someone who attempts to handle his own churning thoughts as best he can.

When I got to know the interviewees, all of them had long-term experience of abusing narcotic substances and of mental health problems. They therefore represented at least two minorities those with mental difficulties and those with abuse problems. At the same time they distinguish themselves somewhat from both these minority groups, quite simply by being members of 
both at the same time. However, they tell of how their drug abuse is first and foremost seen, and commented upon, and that they initially try to distance themselves from other people's preconceptions of the drug-abusing minority (the master narratives). The individuality which in their case includes mental health problems is not seen or is reduced to a consequence of their substance abuse. Like August, all the interviewees tell of support measures not being suitable. The offers are adapted to people with one problem or another, not those who have both problems (or several problems) in combination. Dagfinn stresses: "I have been in the care of both the psychiatry and addiction services, but I do not fit in anywhere. At each of the places they sent me to the other." Several of the other interviewees have the same experience. They describe how the drug abuse is expected to be resolved before health care, that the support services see the drug abuse as the cause and churning thoughts as the effect. For the interviewees, churning thoughts are the cause, and drug abuse is most often a management strategy. However, being rejected by the support services tells them that they are different to other people seeking support from the addiction and psychiatry services. They drop outside society and experience that they are not taken seriously. These experiences join the sequence of events which quite specifically tells them that they are different to most people, and, in these situations, also to the drugabusing minority. All the interviewees' abuse narcotic substances, and in their stories we can recognize the master narratives about the drug abuser. Despite this, all of them tell their unique personal narratives.

\section{The others' perspective defines self-narratives}

Several of the interviewees attempted to describe themselves as being better than other drug abusers. They spoke about their drug abuse not being as severe as other abusers' substance abuse, that they use "softer" drugs than others, that they tackle the consumption of narcotic substances better than others or that they have a better background than them. Erik was one of those who attempted to appear less affected than other drug abusers and less affected than he may be defined as when seen from the outside. When Erik spoke about another drug abuser he described the other person as follows: "He's a junkie, let's put it that way." Erik was quick to add: "I have never been like that. Even though I have done a lot of drugs, I have never been like that." He wants to differentiate himself from the other person in the sense that his drug abuse is not as serious.

According to Erik the term "junkie" describes someone who injects heroin. Erik spoke of how he has no experience of this type of substance abuse. There is however a certain self-contradiction in his self-narrative. He spoke of how he has used the following narcotic substances: "I have used opiates, benzodiazepines, cocaine, amphetamines and ecstasy. I have injected cocaine, amphetamines and morphine." He also speaks of how he receives methadone as part of his medically assisted rehabilitation. This measure indicates (and requires) that he has had heavy and long-term opiate abuse. Erik explained the service by saying that he has smoked a lot of heroin, but says he has never has injected it. He has, however, taken other narcotic substances using syringes. His drug abuse can therefore be defined as relative compared to the drug abuse of "the junkies", whom Erik himself distances himself from. In the narrative Erik also emphasised - in the same way as the master narratives about drug abusers - that being a junkie implies having no accommodation, further education or job. Erik also makes the point that this type of drug abuser has a difficult family background. He pointed out the following:

"I am thinking about the lifestyle of many drug addicts, particularly those who do not have much money and have few resources from before. Those people who come from homes which have few resources. There is often a connection. Drug addicts often come from homes with few resources, with bad parents with poor financial circumstances. Thankfully this is not the case with me...".

Erik also distances himself from "the junkies" when thinking about his growing up. They 
are people further down the ladder than him. He stresses that he has a better starting point than them. Erik's parents have socially acceptable jobs and are well off. However, Erik undercommunicates that he had a difficult upbringing in areas other than economy. Although his parents have a high social and financial status it was not easy for him to live with them. $\mathrm{He}$ and his mother have always had major conflicts. Physical violence has been a natural part of the relationship between them. Erik makes his mother responsible for childhood conflicts. "She is not good, very unstable if you ask me." He therefore learned early from his mother - the significant other - that aggression and hitting are respectable ways of resolving conflicts. He got to know himself and others through interaction and by mimicking his mother, who was a significant role model in his upbringing. According to George H. Mead people's consciousness of themselves develops gradually through interaction with others. The same applies to their self-discipline. First the child mimics others' actions, then the child becomes conscious of the other person and finally the child becomes conscious of himself/herself by taking in the others - the generalised others. "The generalised other" is Mead's term for a composite representation or structuring of attitudes to the others (social morality). The term represents internalised social conscience (Mead 1936). This means that when someone takes in the attitudes of the community, society can exercise a certain amount of control and influence over his conduct and life. Aggression became a known and familiar way of acting to Erik during his childhood. Growing up with violent conflicts left its mark on his way of thinking and acting. As an adult his actions in the world and his self-narrative contribute to him being defined as weak in terms of resources, albeit not financially.

Although Erik would like to appear less burdened than other drug abusers he uses the word "ruffian" when speaking about himself. He defined ruffian as being "a troublesome drug addict who hits people". He says each new day begins with him getting methadone from the municipality's care service. He lives in a supervised local authority flat. He receives rehabilitation payments from the Norwegian Labour and Welfare Administration, but his finances are dictated by the municipality's social work office. He also communicated that he uses illegal narcotic substances and that at times he uses his fists when he believes the situation calls for it. In doing so he gave me a brief description of himself as an outsider. Erik conforms with neither the legal rules of Norwegian society nor the norms which apply to social conduct in the local environment in which he lives. His breaking of rules and norms contributes to him being defined as dangerous and to shutting him out of the community. "People cross the street when they see me," he says. Repeating the label or category of "ruffian" in his conversation with me is not necessarily him agreeing with it. However, him repeating it contributes to maintaining the impression that he is a troublesome drug addict who hits people and has to be kept under supervision. The categorisation is actually used as an aid to creating an opinion, both for him and for those with whom he associates.

The individual takes in others' shared opinions through language in such a way that the individual comes to assume the same attitude to themselves as the community has to him or her (Mead 1936). People who fall into a deviant category and who share experiences linked to membership of the category may gradually come to share society's perceptions and attitudes about themselves (Goffman 1990). They will then conduct themselves as us and as they themselves expect a drug abuser (or a ruffian) to conduct. The others' perspective has become their perspective. This implies that the deviant category drug abuser and the master narratives about or preconception of the deviant category has gradually internalised itself in their thoughts. The master narratives about the drug abuser dominate the interviewees' self-narratives and selfimage. Erik becomes the person that he and others define him as. Today he is a "ruffian" and other people are afraid of him.

The interviewees are all different as individuals, but there are also many similarities between their self-narratives and lives. They have a manner, use of language and appearance leading to them being perceived as similar and often as similarly burdened. Their work in negotiating 
and speaking of unique individuality is difficult when they live (or have lived) as active drug abusers. After many years' with churning thoughts, drug abuse, different services' and different income-earning activities it is difficult for those around them and for themselves to see their individuality - their mental health problems, their skills and their expertise. The interviewees have gradually assumed the others' perspective, and look at themselves in the same way as other people do, a view infiltrating my master narratives about the (male) drug abusers, also female storytellers in my study.

\section{Conclusion}

In this article I have thematized the self-narratives of 17 people in their twenties who abuse narcotic substances. To the mainstream population all 17 of the interviewees are first and foremost seen as drug abusers. Their relationship with narcotic substances makes them different to the majority population and this difference often creates a (moral) distance between them and the rest of society. Being a drug abuser has become the interviewees' master status. Their status as drug abusers makes them visible in social settings but also means that they are overlooked as individuals. The interviewees insist that their substance abuse represents only a small part of their presence in the world and that the relationship only describes their relationship with narcotic substances. But it is difficult for people unfamiliar with this to follow their line of reasoning. The interviewees describe themselves and their existence relatively similarly, both directly and indirectly. They have accumulated special expertise - street capital - which cannot be used anywhere else than in the drug-abusing environment. Their experience causes them difficulties in everyday life, in the labour and housing markets and in relation to the welfare state. Past experiences have left their mark in and on their bodies and many of the experiences afflict them in their churning thoughts world. They have a habitus and a body telling the story of their lifestyle and status as drug abusers. The drug abuser in the master narratives hides the complexity and nuances in their self-narratives. This prevents them and others from seeing and hearing anything other than their own predefined views.

Having said this, what is the message of this article? My aim with this article is to point out that master narratives influence what we all think about ourselves and others. And especially that master narratives concerning the drug abusers hide a person's individuality and their mental health problems when he or she is identified as a drug abuser. I believe, in accordance with Bauman (2004) and Giddens (1991), that we all live in a period of time where we have to negotiate about what kind of identity we can perform and have. It is more difficult to narrate or present a cultural tolerable way of being and living when your body, your experience and your habitus gives away your drug abuser-status. The status refuses them to perform or to tell about their individual identity. However, if we listen carefully and look properly, a drug-addicted storyteller steps out of the drug abuser-narrative and becomes an individual.

Perhaps all of us, but particularly researchers and those providing assistance, should listen more carefully to hear the individual drug abusers unique self-narrative. To listen carefully is necessary in order to acquire knowledge about life on the street and to understand the skills and the capital people build up on the street while suffering from genuine mental health problems. And listening is necessary in order to create and provide better health care and social services for people with mental health and drug problems, or dual diagnosis.

In order to succeed in quitting drug abuse it is important to be able to create, talk about and negotiate a "new" identity - an identity not influenced by narratives about drug abusers. Since the abuser's body clearly reveals substance abuse, it is difficult for him or her to get rid of the master status the narratives contribute to create. The same obstacle is created by their churning thoughts, unusual experience and their lack of ordinary everyday skills, such as following the circadian rhythm, cooking dinner, talking to strangers, using a cash dispenser or paying bills. This is what we - the community - have to take into consideration when we talk to and wish to 
help people who use or have used narcotic substances.

\section{Literature}

Bauman, Zygmunt (2004): Wasted lives. Modernity and its Outcasts. Cambridge, Polity Press

Becker, Gay (1997): Disrupted Lives. How People Create Meaning in a Chaotic World.

Berkeley: University of California Press

Becker, Howard S. (1991): Outsiders. Studies in the sociology of deviance. New York. The Free Press

Bucciarelli, Carol (2005): Addictwd and Mentally ill. Stories of Courage, Hope, and Empowermnt. London, The Haworth Press

Bourdieu, Pierre and Wacquant, Loic J. D. (1992): An invitation to reflexive sociology. Cambridge: Polity Press

Bourdieu, Pierre (1984): Distinction: a social critique of the judgement of taste London: Rutledge \& Kegan Paul

Crossley, Nick (2001) Habit, Identity and Desire. London: SAGE Publications Ltd

Evans, Katie and Sullivan, J. Michael (2001): Dual Diagnosis. Counselling the Mentally III Substance Abuser. New York, The Guilford Press

Fekjær, Hans Olav (2004) Rus. Oslo: Gyldendal Norsk Forlag A/S [Drug]

Frønes, Ivar (2001): Handling, kultur og mening. Bergen, Fagbokforlaget [Action, culture and meaning]

Giddens, Anthony (1991): Modernity and self-identity. Cambridge, Polity Press

Goffman, Erving (1990): Stigma. Notes on the Management of Spoiled Identity. London: Penguin Books

Holstein, James A. and Gubrium, Jaber F. (2004): "The active interview". In Silverman (edited): Qualitative Research - Theory, Method and Practice. London, SAGE Publications

Kandel, Denise B. (2002): Stages and Pathways of Drug involvement. Examining the Gateway Hypothesis. Cambridge, UK: Cambridge University Press

Mead, George Herbert (1936): Movements of thought in the nineteenth century Chicago: University of Chicago Press. (Works of George H. Mead, volume 2, Edited by Merritt H. Moore) NOU 2003:4 Forskning på rusmiddelfeltet. Oslo: Sosialdepartementet [Research on the substance field]

Rosenthal, Richard (edited): Dual Diagnosis. East Sussex, Brunner-Routledge

Sandberg, Sveinung og Willy Pedersen (2006): Gatekapital. Oslo: Universitetsforlaget - In press: Sandberg, S. Pedersen, W. (2009) Street capital: Black cannabis dealers in a white welfare state. Bristil: Policy Press.

Sennett, Richard (2003): Respect: the formation of character in a world of inequality. London: Allen Lane 
Stortingsmelding nr. 20 (2006-2007): Nasjonal strategi for å utjevne sosiale helseforskjeller. Oslo: Helse- og Omsorgsdepartementet [National strategy to reduce social inequalities in health]

Stortingsmelding nr. 25 (1996-97): Åpenhet og helhet Om psykiske lidelser og tjenestetilbudene. Oslo: Sosial- og Helsedepartementet [Receptiveness and entirety. About mental health and services]

Strand, Thomas W. (2005): "Stakkarslige, dumme, kriminelle eller syke?" ARR. Idéhistorisk tidsskrift nr. 1/2 2005 [Wretched, stupid, criminal or sick?]

Standley, Christine A. (2009): "When Counter Narratives Meet Master Narratives in the Journal Editorial-Review Process. Educational Researcher. (htto://er.aera.net)

Søndergaard, Dorte Marie (2002): "Poststructutalist approaches to empirical analysis" Qualitative studies in edducation, vol 15, no. 2

Thorn, Avril and McLean, Kate C. (2003): "Telling Traumatic Events in Adolescence: A Study of Master Narrative Positioning". In Fivush, Robyn and Haden, Catherine A. Autobiographical Memory and the Construction of a Narrative Self. London, Lawrence Erlbaum Associates publishers

Thommesen, Hanne (2008): Hverdagsliv, selvforståelse og dobbeltdiagnose - om mennesker med uvanlige erfaringer. Bodø: Høgskolen i Bodø [Everyday life, self-esteem and dual diagnosis about people with unusual expiries]

Waterston, Alisse (1993): Street Addicts in the Political Economy. Philadelphia, Temple University Press 